\title{
Postural Control and Sleep Quality in Cognitive Dual Tasking in Healthy Young Adults
}

\author{
Marina Saraiva ${ }^{1,2, *(\mathbb{C})}$, Joel Marouvo ${ }^{1,2}\left(\mathbb{D}\right.$, Orlando Fernandes ${ }^{3}\left(\mathbb{D}\right.$, Maria António Castro ${ }^{1,4,5}$ \\ and João Paulo Vilas-Boas ${ }^{6}$ (D) \\ 1 RoboCorp Laboratory, i2A, Polytechnic Institute of Coimbra, 3046-854 Coimbra, Portugal; \\ duartemarouvo@gmail.com (J.M.); maria.castro@ipleiria.pt (M.A.C.) \\ 2 Faculty of Sports, University of Porto, 4200-450 Porto, Portugal \\ 3 Sport and Health Department, School of Health and Human Development, \\ Comprehensive Health Research Center (CHRC), University of Évora, 7000-671 Évora, Portugal; \\ orlandoj@uevora.pt \\ 4 Department of Mechanical Engineering, University of Coimbra, CEMMPRE, 3030-788 Coimbra, Portugal \\ 5 Sector of Physiotherapy, School of Health Sciences, Polytechnic Institute of Leiria, 2411-901 Leiria, Portugal \\ 6 LABIOMEP-UP, Faculty of Sports and CIFI2D, the University of Porto, 4200-450 Porto, Portugal; \\ jpvb@fade.up.pt \\ * Correspondence: marina.saraiva@outlook.com
}

check for updates

Citation: Saraiva, M.; Marouvo, J.; Fernandes, O.; Castro, M.A.; Vilas-Boas, J.P. Postural Control and Sleep Quality in Cognitive Dual Tasking in Healthy Young Adults. J 2021, 4, 257-265. https://doi.org/ $10.3390 / \mathrm{j} 4030021$

Academic Editor: Jon Øyvind Odland

Received: 3 June 2021

Accepted: 2 July 2021

Published: 5 July 2021

Publisher's Note: MDPI stays neutral with regard to jurisdictional claims in published maps and institutional affiliations.

Copyright: (c) 2021 by the authors. Licensee MDPI, Basel, Switzerland. This article is an open access article distributed under the terms and conditions of the Creative Commons Attribution (CC BY) license (https:/ / creativecommons.org/licenses/by/ $4.0 /)$.

\begin{abstract}
Although sleep quality disorders can have a negative effect on postural control, studies about this subject are scarce. The aim of this study is to assess the differences in standing posture performance during dual tasking between healthy young adults with a good and poor sleep quality. Thirty-five healthy participants $(23.09 \pm 3.97$ years) performed a postural task (standing posture single task ((ST)) and a dual task (DT): quiet standing while performing a concurrent cognitive task, while the total excursion of the center of pressure (TOTEX CoP), the displacement anterior-posterior (CoP-AP) and medial-lateral (CoP-ML), the mean total velocity displacement of CoP (MVELO $\mathrm{CoP})$ and ellipse sway area (CEA) were measured with a force plate. After assessing the sleep quality with the Pittsburgh Sleep Quality Index, they were divided into two groups (good $((n=21))$ and poor $((n=14))$ sleep quality) to establish comparisons. This study revealed no significant differences in TOTEX CoP, CoP-ML, CoP-AP, MVELO CoP, and CEA among both sleep quality groups. In conclusion, differences in the sleep quality (good or poor sleep quality) among young adults appear not to be a relevant factor in the CoP variation, but the DT versus ST can compromise postural control performance independently of the sleep quality.
\end{abstract}

Keywords: postural control; dual task; sleep quality; center of pressure

\section{Introduction}

Postural control results from the complex integration of the central nervous system with the visual, vestibular, proprioceptive, and musculoskeletal systems. Maintaining adequate postural control during quiet standing or walking is fundamental to perform daily life activities and preventing injuries or falls. During quiet standing, the center of pressure $(\mathrm{CoP})$ is constantly readjusted to achieve human balance and to counteract the sway of the body; for this reason, $\mathrm{CoP}$ is the measure more used to assess postural sway during static postural control [1].

Postural control integrates the postural orientation and postural equilibrium, these processes are fundamental requirements to stabilize the body and to maintain balance in an upright stance, and thus it is very important for successful performance of movements [2]. The quiet standing position is a complex task that involves the integration of multiple body segments, musculoskeletal and proprioceptive systems with the aim to regulate balance while staying upright in a static position. The standing posture is a requisite basic to perform different tasks, from reaching to locomotion [3]. The posture provides 
the mechanical support and anticipatory postural adjustments necessary for performing movements with an adequate support $[4,5]$.

In daily life, it is common to perform activities in which a postural task (e.g., quiet standing or walking) is executed concurrently with a secondary task (motor or cognitive task). The relationship between attention and postural control is an increasing area of study that has revealed important aspects of the cognitive processing role in postural control. The most used methodology to ascertain its relationship is the dual-task paradigm, in which the postural control (primary task) and a secondary task are performed simultaneously [6]

The postural control system declines with age $[7,8]$ and clinical conditions (e.g., Parkinson's disease, multiple sclerosis) $[9,10]$. During dual-task performance it is expected to observe some changes in CoP behavior; these changes are more evident in the elderly, where they are characterized by higher values of sway area and center of pressure velocity during dual tasks, comparatively to young adults [11]. Recently sleep quality has been an object of study in the performance of postural control. Changes in sleep quality seem to have a negative impact on postural control performance [12] and result in higher gait variability during cognitive dual tasking compared to single tasking (e.g., only walking) [13]. In those with clinical conditions (e.g., fibromyalgia) there is also a decline in postural performance and fall risk compared to healthy people related to sleep quality [14]. Thus, evidence suggests that sleep quality disorders can modify the efficacy of task execution or motor response during dual-task performance.

Good sleep quality can be considered a predictor of physical and mental health, wellness, and vitality [15]. Therefore, sleep is essential for health, and insufficient sleep duration, irregular timing of sleep, poor sleep quality, and circadian/sleep disturbances can cause disorders in people's health [16]. Essential sleep duration conditions differ across the lifespan and from person to person. For healthy people and people without sleep disorders, the recommendation is 7 to $9 \mathrm{~h}$ of sleep per night in adults aged 18 to 64 years [17].

Sleep quality is an unclear term but, in scientific research, the Pittsburgh Sleep Quality Index (PSQI) provides a measure of global sleep quality, including subjective sleep quality, sleep latency, sleep duration, habitual sleep efficiency, sleep disturbances, use of sleeping medication and daytime dysfunction $[18,19]$.

There is a lack of studies among young adults and healthy people on the postural control and quality of sleep in dual-task performance; therefore, the aim of this study is to assess differences in standing posture performance $(\mathrm{CoP})$ during cognitive dual tasking between healthy young adults with a good and poor sleep quality. A secondary aim is to analyze the differences in CoP among single and cognitive dual tasking within each sleep quality group.

\section{Materials and Methods}

After checking the eligibility criteria, thirty-five young adults were recruited. The inclusion criteria for this study were: healthy young adults (18-35 years). Exclusion criteria included: (1) diseases or injuries that affect the musculoskeletal, nervous, and/or cardiorespiratory system, (2) being on medication, (3) recent surgeries (within less than two months) that interfere with gait, (4) visual impairment or vision not corrected to normal vision, (5) vestibular disorders.

All procedures were conducted in compliance with the Declaration of Helsinki and, after a detailed description of the objectives and research methodology, all subjects that agreed to participate read and signed informed consent. This study was approved by the Ethics Committee of the Polytechnic Institute of Coimbra (approval number: 27_CEPC2/2019, and date of approval 26 November 2019).

Sleep quality was assessed using the PSQI. It is a valid and reliable instrument used to assess the quality and patterns of sleep with the advantage of allowing differentiation between good and poor adult sleepers. It differentiates "poor" from "good" sleep by measuring the seven domains (subjective sleep quality, sleep latency, sleep duration, habitual sleep efficiency, sleep disturbances, use of sleeping medication, and daytime 
dysfunction). To each component is assigned a score between 0 to 3 , with 0 being the very good sleep and 3 very bad sleep, where a total equal to or less than 5 points means a good sleep quality and values greater than 5 correspond to poor sleep quality [18].

After assessing sleep quality, the thirty-five healthy young adults ( $23.09 \pm 3.97$ years) were divided into two groups: the good sleep quality group $(n=21)$ and the poor sleep quality group $(n=14)$.

A Bertec ${ }^{\circledR}$ force plate, model FP4060-07-1000 (Bertec Corporation, 6171 Huntley Road, Suite J Columbus, OH 43229, USA) with a maximum capacity of $5000 \mathrm{~N}$ was used to measure total excursion of the center of pressure (TOTEX CoP—unit in $\mathrm{mm}$ ), the displacements of the center of pressure in medial-lateral (CoP-ML-unit in $\mathrm{mm}$ ) and anterior-posterior (CoP-AP-unit in $\mathrm{mm}$ ) directions, the mean total velocity displacement of CoP ((MVELO $\mathrm{CoP}$ - unit in $\mathrm{mm} / \mathrm{s}$ ) and $95 \%$ confidence ellipse sway area (CEA-unit in $\mathrm{mm}^{2}$ ). The force plate data were filtered using a $50 \mathrm{~Hz}$ low-pass filter, 6th Butterworth and they were processed after the assessment with a Matlab routine (version R2020b, Mathworks, Inc., Natick, MA, USA).

All participants underwent anthropometric measurements (weight and height) before performing tasks. Then, they were instructed to stand as still as possible in a quiet standing position while focusing on a point at eye-level of the participants (single task-standing posture) for $60 \mathrm{~s}$ [20].

The dual task consisted of keeping a quiet standing position while performing a concurrent cognitive task-arithmetic or memory tasks (cognitive dual task) on their smartphone for $60 \mathrm{~s}$. The arithmetic task consisted of a sum or subtraction calculation with one or two digits (e.g., $6+20=$ ?; $9+?=58$ ). The memory task consisted of memorizing three elements (number, color of the number and image) and then repeating the memorized elements for a few seconds. For each participant, the cognitive task was chosen randomly. The cognitive task performance on the baseline (sitting in the chair while cognitive task performing) and on the dual task (quiet standing position while performing a concurrent cognitive task) was estimated by the number of correct responses in each task.

Each participant repeated each task once, with a one minute rest period between the tasks. No priority was given to cognitive and standing postural tasks. The participants were instructed to use their personal smartphone and hold it in the usual way while performing the cognitive task.

The statistical analysis was conducted using IBM-SPSS 25.0 software. Quantitative descriptive data related to sample characteristics are reported as mean $\pm \mathrm{SD}$ (standard deviation). Homogeneity of variances and normality of the distribution of the parameters was tested with the Levene's and Shapiro-Wilk tests, respectively. Some outcomes were not normally distributed; thus, the data were presented as the median and interquartile range (IQR). The differences between groups with different sleep quality scores were assessed through the Mann-Whitney $U$ test. The differences in dual-task performance within each group were analyzed with the related samples Wilcoxon signed-rank test. The statistical significance level was set at $p<0.05$.

\section{Results}

\subsection{Sample Characteristics}

Table 1 shows the participants' characteristics. There was no difference between the good and poor sleep quality groups for anthropometric characteristics $(p>0.05)$. There was a significant difference in the total score of the PSQI between the good ( $3.78 \pm 1.40$ points) and poor $(8.29 \pm 2.05$ points) sleep quality groups $(p<0.001)$.

The cognitive task performance on the baseline (sitting while performing cognitive task) and on the dual task (maintaining a quiet standing position while performing a concurrent cognitive task) did not differ between good and poor sleep quality groups or within each group $(p>0.05)$. 
Table 1. Anthropometrics characteristics and total PSQI score of the total sample and sleep quality groups (mean $\pm \mathrm{SD}$ ).

\begin{tabular}{cccc}
\hline Variables & Sample $\boldsymbol{n = 3 5}$ & $\begin{array}{c}\text { Good Sleep Quality Group } \\
(\boldsymbol{n}=\mathbf{2 1})\end{array}$ & $\begin{array}{c}\text { Poor Sleep Quality Group } \\
(\boldsymbol{n}=\mathbf{1 4})\end{array}$ \\
\hline Age (years) & $23.09 \pm 3.97$ & $22.38 \pm 4.20$ & $24.14 \pm 3.48$ \\
Height $(\mathrm{m})$ & $1.71 \pm 0.10$ & $1.73 \pm 0.08$ & $1.68 \pm 0.12$ \\
Weight $(\mathrm{Kg})$ & $73.53 \pm 15.96$ & $74.32 \pm 13.35$ & $72.34 \pm 19.74$ \\
BMI $\left(\mathrm{Kg} / \mathrm{m}^{2}\right)$ & $25.07 \pm 4.41$ & $24.86 \pm 3.72$ & $25.37 \pm 5.40$ \\
PSQI total & $5.40 \pm 2.91$ & $3.78 \pm 1.40^{1}$ & $8.29 \pm 2.05^{1}$ \\
\hline
\end{tabular}

BMI, body mass index; PSQI, Pittsburgh Sleep Quality Index. ${ }^{1} p<0.01$ between two sleep quality groups using Mann-Whitney U test.

\subsection{Postural Outcomes}

\subsubsection{CoP among Good Sleep and Poor Sleep Quality Groups}

There were no significant differences in the total excursion of the center of pressure, in the displacements of the center of pressure in anterior-posterior and medial-lateral directions (statokinesigram in Figure 1), in the mean total velocity displacement of CoP, and in the $95 \%$ confidence ellipse sway area during standing posture between the good sleep and poor sleep quality groups $(p>0.05)$. CoP data (median, IQR) and statistical comparisons among groups (Mann-Whitney $\mathrm{U}$ test, $p$-value) during standing posture (single task) are summarized in Table 2.
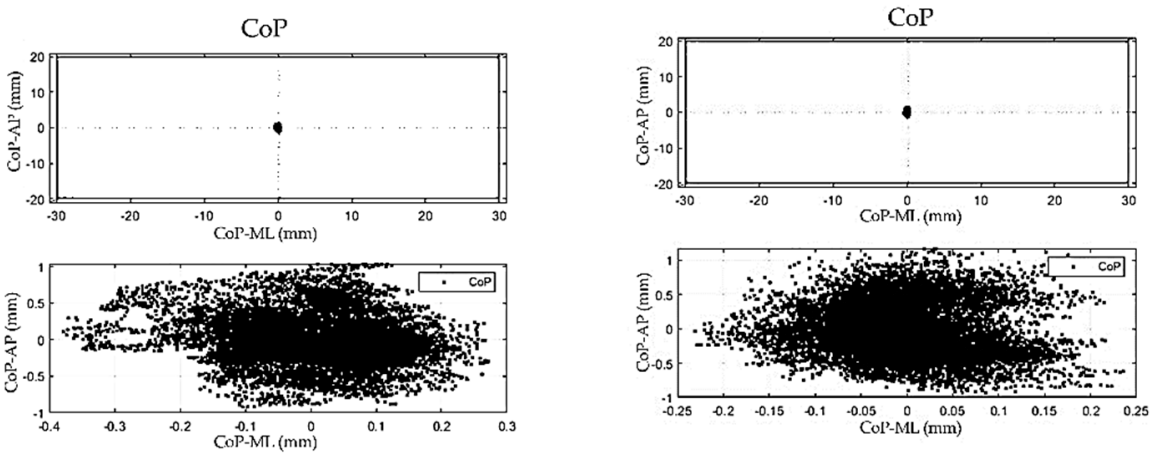

(a)

(b)

Figure 1. Statokinesigram: displacements of the center of pressure in anterior-posterior and mediallateral directions during single task: (a) good sleep quality group; (b) poor sleep quality group $(p>0.05)$.

Table 2. Comparisons of center of pressure (CoP) behavior among good and poor sleep quality groups during standing posture task (single task), median (IQR).

\begin{tabular}{cccc}
\hline Outcomes & $\begin{array}{c}\text { Good Sleep Quality Group } \\
(\boldsymbol{n}=\mathbf{2 1})\end{array}$ & $\begin{array}{c}\text { Poor Sleep Quality Group } \\
(\boldsymbol{n}=\mathbf{1 4})\end{array}$ & $\boldsymbol{p}$-Value $\mathbf{1}^{\mathbf{1}}$ \\
\hline TOTEX CoP $(\mathrm{mm})$ & $2449.8(2217.4-2665.8)$ & $2376.9(2104.1-3032.7)$ & 0.814 \\
CoP-AP (mm) & $1848.3(1684.6-2010.7)$ & $1801.4(1613.0-2267.9)$ & 0.840 \\
CoP-ML (mm) & $1215.7(1125.3-1347.9)$ & $1224.7(1034.1-1582.1)$ & 0.762 \\
CEA $\left(\mathrm{mm}^{2}\right)$ & $215.7(106.9-386.3)$ & $234.7(114.2-361.7)$ & 0.762 \\
MVELO CoP $(\mathrm{mm} / \mathrm{s})$ & $490.0(443.5-533.2)$ & $475.4(420.8-606.5)$ & 0.814 \\
\hline
\end{tabular}

TOTEX CoP, total excursion of the center of pressure; CoP-AP, displacement of the center of pressure in anterior-posterior direction; CoP-ML, displacement medial-lateral direction; MVELO CoP, mean total velocity displacement of CoP; CEA, 95\% confidence ellipse sway area. ${ }^{1}$ Mann-Whitney U test.

The area of the confidence ellipse during single and cognitive dual tasking was lower in the good sleep quality group (ST-median: $215.7((106.9-386.3)) \mathrm{mm}^{2}$; DT$\left.552.1((235.0-1029.6)) \mathrm{mm}^{2}\right)$ in comparison to the poor sleep quality group (ST-median: $234.7((114.2-361.7)) \mathrm{mm}^{2}$; DT-726.5 ((493.9-1448.2)) $\left.\mathrm{mm}^{2}\right)$, but this difference was not significant $(p>0.05)$. 
During dual-task performance (quiet standing position while concurrently performing a cognitive task) there were no significant differences in all CoP variables between the good and poor sleep quality groups $(p>0.05)$. The statokinesigram representative of the displacement of the center of pressure in anterior-posterior and medial-lateral directions between the sleep quality groups during cognitive dual tasking is illustrated in Figure 2. The CoP data (median, IQR) and statistical comparisons between sleep quality groups (Mann-Whitney $\mathrm{U}$ test, $p$-value) during dual tasking are shown in Table 3.
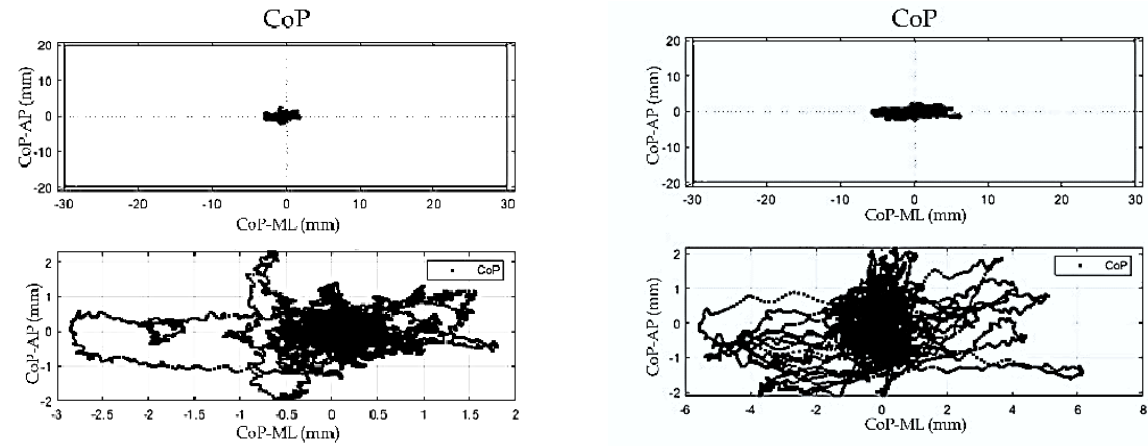

(a)

(b)

Figure 2. Statokinesigram: displacements of the center of pressure in anterior-posterior and mediallateral directions during dual tasking: (a) good sleep quality group; (b) poor sleep quality group $(p>0.05)$.

Table 3. Comparisons of CoP behavior among good and poor sleep quality groups during quiet standing position while performing a cognitive task (dual task), median (IQR).

\begin{tabular}{|c|c|c|c|}
\hline Outcomes & $\begin{array}{l}\text { Good Sleep Quality Group } \\
\qquad(n=21)\end{array}$ & $\begin{array}{l}\text { Poor Sleep Quality Group } \\
\qquad(n=21)\end{array}$ & $p$-Value ${ }^{1}$ \\
\hline TOTEX CoP (mm) & $2648.5(2421.0-3058.1)$ & $2497.5(2364.8-3307.0)$ & 0.946 \\
\hline CoP-AP (mm) & $2010.2(1843.0-2347.0)$ & $1924.4(1765.0-2457.8)$ & 0.866 \\
\hline CoP-ML (mm) & 1292.9 (1189.5-1412.7) & 1266.8 (1190.5-1817.5) & 0.736 \\
\hline $\mathrm{CEA}\left(\mathrm{mm}^{2}\right)$ & $552.1(235.0-1029.6)$ & 726.5 (493.9-1448.2) & 0.281 \\
\hline MVELO CoP (mm/s) & 529.7 (484.2-611.7) & 499.5 (473.0-661.5) & 0.946 \\
\hline
\end{tabular}

TOTEX CoP, total excursion of the center of pressure; CoP-AP, displacement of the center of pressure in anterior-posterior direction; CoP-ML, displacement medial-lateral direction; MVELO CoP, mean total velocity displacement of CoP; CEA, 95\% confidence ellipse sway area. ${ }^{1}$ Mann-Whitney U test.

\subsubsection{CoP Comparisons among ST and DT within Each Sleep Quality Group}

Within each group, between single and dual-task performance, there was a significant difference $(p<0.05)$ in the total excursion of the center of pressure, in the displacements of the center of pressure in the anterior-posterior and the medial-lateral directions, in the mean total velocity displacement of $\mathrm{CoP}$ and the $95 \%$ confidence ellipse sway area. These data are summarized in Table 4.

Table 4. Comparisons of postural outcomes between single and dual-task conditions within good sleep quality group and poor sleep quality group, median and $p$-values.

\begin{tabular}{ccccc}
\hline Outcomes & $\begin{array}{c}\text { Good Sleep Quality Group } \\
(\boldsymbol{n}=\mathbf{2 1}) \text { ST vs. DT }\end{array}$ & $\boldsymbol{p}$-Value $\mathbf{1}^{\mathbf{1}}$ & $\begin{array}{c}\text { Poor Sleep Quality Group } \\
(\boldsymbol{n}=\mathbf{1 4}) \text { ST vs. DT }\end{array}$ & $\boldsymbol{p}^{\text {-Value }} \mathbf{1}^{\mathbf{1}}$ \\
\hline TOTEX CoP $(\mathrm{mm})$ & 2449.8 vs. 2648.5 & 0.002 & 2376.9 vs. 2497.5 & 0.001 \\
CoP-AP $(\mathrm{mm})$ & 1848.3 vs. 2010.5 & 0.001 & 1801.4 vs. 1924.4 & 0.002 \\
CoP-ML (mm) & 1215.7 vs. 1292.9 & 0.008 & 1224.7 vs. 1266.8 & 0.002 \\
CEA (mm $\left.{ }^{2}\right)$ & 215.7 vs. 552.1 & 0.000 & 234.7 vs. 726.5 & 0.002 \\
MVELO CoP $(\mathrm{mm} / \mathrm{s})$ & 490.0 vs. 529.7 & 0.002 & 475.4 vs. 499.5 & 0.001 \\
\hline
\end{tabular}

TOTEX CoP, total excursion of the center of pressure; CoP-AP, displacement of the center of pressure in anterior-posterior direction; CoP-ML, displacement medial-lateral direction; MVELO CoP, mean total velocity displacement of CoP; CEA, 95\% confidence ellipse sway area; ST, single-task; DT, dual task. ${ }^{1}$ Related samples Wilcoxon signed-rank test. 


\section{Discussion}

This study investigated the differences in static postural control between good and poor sleep groups during a single task (quiet standing position) and cognitive dual task (quiet standing position while performing a concurrent cognitive task), in healthy young adults.

The current study results showed that variability of the center of pressure during single and dual tasks does not differ between good and poor quality sleep groups in healthy young adults. As such, it is suggested that in this study sample sleep quality does not compromise the total excursion of the center of pressure, the displacements of the center of pressure in anterior-posterior and medial-lateral directions, the mean total velocity displacement of $\mathrm{CoP}$, and the $95 \%$ confidence ellipse sway area during the static postural control (standing posture) and the dual-task performance.

Although these results were not significant, which challenges comparison, concerning the $95 \%$ area of the confidence ellipse during single and cognitive dual tasking we found a lower CEA in subjects that show a good sleep quality compared to the poor sleep quality group. The reduced area postural sway in the good quality group can suggest an effectiveness of postural control and lower risk of fall. Previous studies demonstrate that a greater $95 \%$ confidence ellipse area can be associated with an ineffectiveness of postural stability [21] and a fall history in older people [22].

There are few studies comparing groups with different sleep quality in postural control performance or/and during dual-task performance. A study that assessed the static and dynamic postural control performance under conditions that alter sensory inputs (e.g., eyes open or closed, rigid or soft surface), between higher and lower sleep quality groups using the PSQI and an actigraphy to evaluate the sleep quality in healthy young adults also found no significant differences in static postural control (eyes open-firm surface, eyes closed-firm surface, eyes open-foam surface conditions) between the sleep quality groups. However, in the static postural test with eyes closed on a foam surface, they found a significant difference between groups (lower sleep quality group with worse performance in static postural control). During dynamic postural control, they found that the lower sleep quality group presented a worse performance in postural control than the higher sleep quality group in most dynamics tests [12].

Another study analyzed the relationship between gait performance and sleep behavior during single tasks and dual tasks in older adults. It was found that a lower sleep efficacy was associated with decreased gait speed and increased gait variability during cognitive DT (walking while concurrently performing a cognitive task) but found no correlations between sleep and gait measures during the single task (walking only) [13]. Our study found, within each group, the worst results in the total excursion of the center of pressure, in the displacements of the center of pressure in the anterior-posterior and medial-lateral directions, in the mean total velocity displacement of CoP, and the $95 \%$ confidence ellipse sway area during the cognitive dual task compared to the single task, regardless of the sleep quality. An explanation for this may be that the performance decrements during the cognitive dual task could be related to the prioritization task and the individual's skills to allocate their cognitive resources [6,23]; in this case, the participants could be more involved in the cognitive task performance than in maintaining balance in the quiet standing posture.

In challenging postural conditions (reduced base support, vision deprivation, cognitive load) the velocity of $\mathrm{CoP}$ increases but the $\mathrm{CoP}$ displacements decrease during dual tasking, likely due to enhanced lower limb stiffness in healthy adults [24]. Similarly, our results showed an increase in the mean total velocity displacement of CoP of healthy young adults while performing a cognitive task when compared to the single postural task, using a relatively easy postural task (quiet standing position with eyes open) and a cognitive task with some load.

Most studies attempt to establish associations between sleep quality and cognitive or school performance. In our case, there were no differences between good and poor sleep quality groups or within each group regarding cognitive task performance. Similarly, 
other authors showed that there was no association between sleep quality and cognitive performance (working memory, executive functions and procedural learning) in healthy young adults [25]. Contrarily, other research showed a strong association between worse school performance and sleep disturbances (poor sleep quality, insufficient duration sleep and sleepiness) [26], emphasizing the importance of sleep in cognitive functioning, in the performance of cognitive-motor dual tasks and in daily life conditions. Furthermore, it showed an association between sleep disturbances (e.g., a higher number of awakenings) and a detriment of dual-task performance in children [27].

The current study has some strengths and weaknesses. A major strength was that static postural control was measured objectively in single and dual tasks in the different sleep quality groups. Our study contributed more information about the comparisons between sleep quality and dual-task performance in healthy young adults. Relative to the task choice, we used a smartphone to allow performing dual tasks because we wanted to reproduce the usual situations of daily life; in this case, the dual task was to keep a quiet standing position while the participant played a cognitive game on the smartphone. Our results represented the assessment of sleep quality and postural control in the cognitive dual task in healthy individuals, contrary to other studies that describe postural stability after sleep deprivation and/or with visual manipulation [28-30]. Thus, our results characterize the real environment and add information about the normal sleep condition (normal sleep night) and its influence on postural control in dual tasking in healthy young adults.

A limitation was the sample size was not large enough to create different sleep quality groups with a greater sample number and to facilitate adequate statistical power. Some studies analyze the sleep quality in sleep privation conditions, and they find that alterations in sleep quality and pattern during consecutive days can affect balance [31,32]. We used the PSQI to assess the subjective sleep quality during the previous month only and the results of total score PSQI in the global sample $(n=35)$ approached a better sleep quality than poor sleep quality, and this can have contributed to no difference in postural control between sleep quality groups.

We suggest a better understanding of the influence on sleep quality in postural control performance during dual tasking because sleep can steady and improve the consolidation of gross motor tasks in healthy adults, despite the fact this association among learning and sleep parameters is still controversial [33].

\section{Conclusions}

Good or poor sleep quality in healthy young adults appears not to be a relevant factor influencing $\mathrm{CoP}$ variation. However, intra-group changes were observed in all CoP variables in a study during cognitive dual tasking versus single task performance and this suggests that while performing dual tasks the postural control is negatively affected, resulting in a greater oscillation and compromising the postural control independently of the sleep quality.

Author Contributions: Conceptualization, M.S.; methodology, M.S.; software, J.M., O.F. and M.A.C.; validation, M.S., J.P.V.-B. and M.A.C.; formal analysis, M.S., J.M., O.F. and M.A.C.; investigation, M.S., J.P.V.-B. and M.A.C.; resources, M.S., J.M., O.F. and M.A.C.; data curation, M.S.; writing—original draft preparation, M.S.; writing - review and editing, M.S., J.P.V.-B. and M.A.C.; visualization, M.S.; supervision, J.P.V.-B. and M.A.C.; project administration, M.S., J.P.V.-B. and M.A.C. All authors have read and agreed to the published version of the manuscript.

Funding: This research did not receive external funding.

Institutional Review Board Statement: The study was conducted according to the guidelines of the Declaration of Helsinki and approved by the Ethics Committee of the Polytechnic of Coimbra (approval number: 27_CEPC2/2019 and date of approval 26 November 2019).

Informed Consent Statement: Informed consent was obtained from all subjects involved in the study. 
Data Availability Statement: The data presented in this study are available on request from the corresponding author.

Acknowledgments: We gratefully acknowledge all participants who contributed to this study.

Conflicts of Interest: The authors declare no conflict of interest.

\section{References}

1. Winter, D.A. Human balance and posture control during standing and walking. Gait Posture 1995, 3, 193-214. [CrossRef]

2. Horak, F.B. Postural orientation and equilibrium: What do we need to know about neural control of balance to prevent falls? Age Ageing 2006, 35 (Suppl. 2), ii7-ii11. [CrossRef]

3. Ku, P.X.; Azuan, N.; Osman, A.; Yusof, A.; Abu, W.; Wan, B. The Effect on Human Balance of Standing with Toe- Extension. PLoS ONE 2012, 7, e41539. [CrossRef] [PubMed]

4. Massion, J. Postural control systems in developmental perspective. Neurosci. Biobehav. Rev. 1998, 22, 465-472. [CrossRef]

5. Wallmann, H.W. The basics of balance and falls. Home Health Care Manag. Pract. 2009, 21, 436-439. [CrossRef]

6. Woollacott, M.; Shumway-Cook, A. Attention and the control of posture and gait: A review of an emerging area of research. Gait Posture 2002, 16, 1-14. [CrossRef]

7. Borah, D.; Wadhwa, S.; Singh, U.; Yadav, S.L.; Bhattacharjee, M.; Sindhu, V. Aged related changes in postural stability. Indian J. Physiol. Pharmacol. 2007, 51, 395-404.

8. Roman-Liu, D. Age-related changes in the range and velocity of postural sway. Arch. Gerontol. Geriatr. 2018, 77, 68-80. [CrossRef]

9. Fukunaga, J.Y.; Quitschal, R.M.; Doná, F.; Ferraz, H.B.; Ganança, M.M.; Caovilla, H.H. Postural control in Parkinson's disease. Braz. J. Otorhinolaryngol. 2014, 80, 508-514. [CrossRef]

10. Cameron, M.H.; Lord, S. Postural Control in Multiple Sclerosis: Implications for Fall Prevention. Curr. Neurol. Neurosci. Rep. 2010, 10, 407-412. [CrossRef]

11. Bergamin, M.; Gobbo, S.; Zanotto, T.; Sieverdes, J.C.; Alberton, C.L.; Zaccaria, M.; Ermolao, A. Influence of age on postural sway during different dual-task conditions. Front. Aging Neurosci. 2014, 6, 271. [CrossRef] [PubMed]

12. Furtado, F.; Gonçalves, B.d.S.B.; Abranches, I.L.L.; Abrantes, A.F.; Forner-Cordero, A. Chronic Low Quality Sleep Impairs Postural Control in Healthy Adults. PLoS ONE 2016, 11, e0163310. [CrossRef] [PubMed]

13. Agmon, M.; Shochat, T.; Kizony, R. Sleep quality is associated with walking under dual-task, but not single-task performance. Gait Posture 2016, 49, 127-131. [CrossRef]

14. Akkaya, N.; Akkaya, S.; Atalay, N.S.; Acar, M.; Catalbas, N.; Sahin, F. Assessment of the relationship between postural stability and sleep quality in patients with fibromyalgia. Clin Rheumatol. 2013, 32, 325-331. [CrossRef] [PubMed]

15. Ohayon, M.; Wickwire, E.M.; Hirshkowitz, M.; Albert, S.M.; Avidan, A.; Daly, F.J.; Dauvilliers, Y.; Ferri, R.; Fung, C.; Gozal, D.; et al. National Sleep Foundation's sleep quality recommendations: First report. Sleep Health 2017, 3, 6-19. [CrossRef] [PubMed]

16. Laposky, A.D.; Van Cauter, E.; Diez-Roux, A.V. Reducing health disparities: The role of sleep deficiency and sleep disorders. Sleep Med. 2016, 18, 3-6. [CrossRef]

17. Hirshkowitz, M.; Whiton, K.; Albert, S.M.; Alessi, C.; Bruni, O.; DonCarlos, L.; Hazen, N.; Herman, J.; Katz, E.S.; KheirandishGozal, L.; et al. National Sleep Foundation's sleep time duration recommendations: Methodology and results summary. Sleep Health 2015, 1, 40-43. [CrossRef]

18. Buysse, D.J.; Reynolds, C.F., 3rd; Monk, T.H.; Berman, S.R.; Kupfer, D.J. The Pittsburgh Sleep Quality Index: A new instrument for psychiatric practice and research. Psychiatry Res. 1989, 28, 193-213. [CrossRef]

19. Krystal, A.D.; Edinger, J.D. Measuring sleep quality. Sleep Med. 2008, 9, S10-S17. [CrossRef]

20. Carpenter, M.G.; Frank, J.S.; Winter, D.A.; Peysar, G.W. Sampling duration effects on centre of pressure summary measures. Gait Posture 2001, 13, 35-40. [CrossRef]

21. Wang, Y.; Watanabe, K.; Chen, L. Effect of plantar cutaneous inputs on center of pressure during quiet stance in older adults. J. Exerc. Sci. Fit. 2016, 14, 24-28. [CrossRef] [PubMed]

22. Merlo, A.; Zemp, D.; Zanda, E.; Rocchi, S.; Meroni, F.; Tettamanti, M.; Recchia, A.; Lucca, U.; Quadri, P. Postural stability and history of falls in cognitively able older adults: The Canton Ticino study. Gait Posture 2012, 36, 662-666. [CrossRef] [PubMed]

23. Dault, M.C.; Geurts, A.C.H.; Mulder, T.W.; Duysens, J. Postural control and cognitive task performance in healthy participants while balancing on different support-surface configurations. Gait Posture 2001, 14, 248-255. [CrossRef]

24. Albertsen, I.A.; Ghédira, M.; Gracies, J.-G.; Hutin, E. Postural stability in young healthy subjects-Impact of reduced base of support, visual deprivation, dual tasking. J. Electromyogr. Kinesiol. 2017, 33, 27-33. [CrossRef] [PubMed]

25. Zavecz, Z.; Nagy, T.; Galkó, A.; Nemeth, D.; Janacsek, K. The relationship between subjective sleep quality and cognitive performance in healthy young adults: Evidence from three empirical studies. Sci. Rep. 2020, 10, 4855. [CrossRef]

26. Dewald, J.F.; Meijer, A.M.; Oort, F.J.; Kerkhof, G.A.; Bögels, S.M. The influence of sleep quality, sleep duration and sleepiness on school performance in children and adolescents: A meta-analytic review. Sleep Med. Rev. 2010, 14, 179-189. [CrossRef]

27. Möhring, W.; Urfer-Maurer, N.; Brand, S.; Holsboer-Trachsler, E.; Weber, P.; Grob, A.; Lemola, S. The association between sleep and dual-task performance in preterm and full-term children: An exploratory study. Sleep Med. 2019, 55, 100-108. [CrossRef] 
28. Robillard, R.; Prince, F.; Filipini, D.; Carrier, J. Aging Worsens the Effects of Sleep Deprivation on Postural Control. PLoS ONE 2011, 6, e28731. [CrossRef]

29. Gomez, S.; Patel, M.; Berg, S.; Magnusson, M.; Johansson, R.; Fransson, P.A. Effects of proprioceptive vibratory stimulation on body movement at 24 and $36 \mathrm{~h}$ of sleep deprivation. Clin. Neurophysiol. 2008, 119, 617-625. [CrossRef]

30. Nakano, T.; Araki, K.; Michimori, A.; Inbe, H.; Hagiwara, H.; Koyama, E. Nineteen-hour variation of postural sway, alertness and rectal temperature during sleep deprivation. Psychiatry Clin. Neurosci. 2001, 55, 277-278. [CrossRef]

31. Montesinos, L.; Castaldo, R.; Cappuccio, F.P.; Pecchi, L. Day-to-day variations in sleep quality affect standing balance in healthy adults. Sci. Rep. 2018, 8, 17504. [CrossRef] [PubMed]

32. Bougard, C.; Lepelley, M.-C.; Davenne, D. The influences of time-of-day and sleep deprivation on postural control. Exp. Brain Res. 2011, 209, 109-115. [CrossRef] [PubMed]

33. Christova, M.; Aftenberger, H.; Nardone, R.; Gallasch, E. Adult Gross Motor Learning and Sleep: Is There a Mutual Benefit? Hindawi Neural Plast. 2018, 2018, 3076986. [CrossRef] [PubMed] 